\title{
Initial Implementation of Constructivist Physics Teaching in Thailand: A Case of Bass Pre-service Teacher
}

\author{
Jiraporn Tupsai \\ Science Education Department, Faculty of Education, Khon Kaen University, Thailand \\ Email: tjirap@kku.ac.th \\ Chokchai Yuenyong \\ Science Education Department, Faculty of Education, Khon Kaen University, Thailand \\ Corresponding Author Email: ychok@kku.ac.th \\ Peter Charles Taylor \\ Science and Mathematics Education Centre, Curtin University, Australia \\ P.Taylor@curtin.edu.au
}

Doi:10.5901/mjss.2015.v6n2p506

\begin{abstract}
The purpose of this study is to investigate a pre-service teacher's initial implementation of constructivist physics teaching. A case study was used to explore the underlying constructivist-based physics teaching implemented by a non-experienced male pre-service physics teacher, Bass. A mixed-methods research design was used to monitor the development of constructivist classroom environment at different phases. To collect quantitative data, the Constructivist Learning Environment Survey (CLES) consisting of 5 elements: Personal Relevance (PR), Student Negotiation (SN), Shared Control (SC), Critical Voice (CV), and Uncertainty (UN) was primarily applied to reflect students' perception toward the pre-service's classroom learning environment after applying constructivist teaching scheme. The supplementary qualitative data were also obtained from classroom observations and interviews between Bass and the author as a teaching coach. The result showed that the preservice teacher could reflect certain elements of constructivist physics teaching, especially PR, SN and SC. It was indicated that his physics lessons significantly became more personally relevant to students' daily life. His students were likely to be more active in class discussion and allowed to question or criticize given class activities. The study contributes to several important implications for future research, particularly in the context of constructivist teaching in developing countries where knowledge concerning science and technology needs to be improved and for the pre-service teacher training program development for the Faculty of Education (Science Teaching) on behalf of Khon Kaen University.
\end{abstract}

Keywords: Physics teaching, Constructivist learning environment, Pre-service teacher, Mixed-methods research.

\section{Introduction}

Today, positive learning environment in classroom is widely accepted as a valuable objective in education (Fraser, 2002; UNESCO, 2003), in the global arena, has proposed thousands of projects to promote science education throughout the world under the belief that the innovation derives from rich science knowledge which allows people to live in a better quality of life with safety and happiness. Like Thailand, a developing country, has also paid great attention to scientific and technological knowledge and skills. Thai National Constitution B.E. 2540 (1999), in terms of science, states that a strong development in science education is required to develop the nation.

In addition, the latest Thai National Education Act of B.E. 2542(2001) section 22 (p.12) states that all learners shall have capability to learn and self-development as well as teaching process shall aim at enabling learners to develop themselves at the own pace with their best potential. Moreover, it is mentioned that Thai science education needs to focus on understanding and experience in conservation and utilization of our national resources and the environment in a balanced and sustainable manner.

However, teaching and learning in Thailand faces with issues. Obviously, the quality of educational provision is poor and unequally distributed. Another critical issue is that teacher-centered and lecture-based instruction has generally dominated in Thai science classrooms. To diminish the issues, the nation's education reform is launched to change 
traditional teaching approach. It aims that science education shall lie with activity-based learning called constructivist learning, which in turn, student-centered instruction shall be raised. Constructivist learning is to allow students to find personal relevance in their studies, share control over their learning, be confident to express questions or concerns about their learning, be aware that science is ever-changing, and interact with others when comprehension is needed to improve (Taylor, 1997).

Constructivist learning, a leading theoretical approach is widely used to drive science education (Steffe, 1995; Tobin 1993). It is powerful to build environment in classroom that maximizes students' learning. Constructivist scientific educators attempts to enhance students' conceptual understanding particularly in science modules.

However, Fraser (1986) argued that quality of classroom environment has a significant impact on students' learning. Thus, the perspective of classroom environment was combined with the constructivist learning approach. There are a number of studies focusing on assessing effect of constructivist learning on students. One of the indicators representing the successful outcome of constructivist learning on students is the positive perceptions of students toward their preferred cognitive and affective learning environment.

This study has presented the importance of constructivist teaching to improve student-centered learning approach based on science education development of national education reform. This study has also proposed practical implications to facilitate practitioners in building student's preferred learning environment and to enhance understanding of constructivist teaching for researchers in the future research.

The aim of the study is to monitor the existence of constructivist classroom environment. The Constructivist Learning Environment Survey (CLES) (Taylor \& Fraser, 1997) provided this opportunity by measuring students' perceptions from five different perspectives and also by the fact that the theory used for development of it was matched with our understanding about the constructivist learning environment. Thus, we utilized this instrument in this study. The CLES could be used for monitor and investigate underlying implementation of constructivist-based physics teaching of a first-time pre-service teacher at different phases by using self-reflection techniques. The reflection is used to identify the improvement of pre-service teachers' implementation of constructivist physics teaching. The research questions are as follows:

1.1 To what extent does the pre-service teacher implement constructivist-based physics teaching by using monitoring CLES?

1.2 How does self-reflection improve pre-service teachers' implementation of constructivist teaching

\section{Literature}

Classroom learning environment research has focused on assessment and improvement of learning and teaching within the context of constructivist learning environment more recently (Aldridge, Fraser, Taylor, \& Chen, 2000; Taylor, Fraser, \& Fisher, 1997). In a constructivist learning environment, teachers are accepted as facilitators and they encourage students for conceptual development. Students use their prior knowledge and reflect upon other students' ideas in the classroom while developing their conceptual understanding of new scientific topics.

The Constructivist Learning Environment Survey (CLES) developed by Taylor \& Fraser (1997) is one of the questionnaires for assessing students' perception of their constructivist-based learning environment in order to reshape teachers' practices. The CLES consists of five six-item scales, namely, Personal Relevance, Uncertainty, Critical Voice, Shared Control and Student Negotiation and will be used in the study. The five elements of CLES could be explained as below.

Personal Relevance (PR) focuses on the connectedness of school where science in students' eyed are based on out-of-school experiences. The everyday use of students' experiences is a meaningful context for the development of students' scientific and mathematical knowledge.

Uncertainty (UN) refers to the extent to which opportunities are provided for students to experience scientific knowledge as arising from theory-dependent inquiry involving human experience and values, and as evolving, nonfoundational, and culturally and socially determined.

Critical Voice (CV) examines the extent to which a social climate has been established where students feel that it is beneficial to question the teacher's pedagogical plans and methods and to express their learning concerns about any issues.

Shared Control (SC) is concerned with students being invited to share with the teacher control of the learning environment, including the articulation of learning goals, the design and arrangement of learning activities, and the determination and application of assessment criteria.

Student Negotiation (SN) is a scale for assessing the extent to which opportunities exist for students to explain and 
justify to other students' newly developing ideas, to listen attentively and reflect on the viability of other students' ideas and, subsequently, and to reflect self-critically on the viability of their own ideas.

\section{Methodology}

In the mix-methods study, both qualitative and quantitative data were used. The quantitative data was designed to measure the incidence of various possible views of factors influencing the constructivist physics teaching implementation while the qualitative study was required to provide insights into the specific pre-service teacher on his natural classroom settings (Creswell \& Plano Clark, 2011).

The quantitative data were collected from the questionnaire as a research tool which was applied from Constructivist Learning Environment Survey (Taylor \& Fraser, 1997). The questionnaire contained 30 questions based on the elements in original CLES to reflect students' perception toward pre-service teacher's constructivist teaching implementation by focusing on his class's learning environment. Then, supplementary qualitative data were collected by classroom observations and interviews between Bass and the author as an observer and a teaching coach.

\subsection{Participant}

In the case study, the participant was a male prospective physics teacher, called a pre-service teacher who was teaching in grade 11. His pseudonym was Bass. The participant was selected because of several justified reasons. First, he was an undergraduate student in the program of Science Education (Teaching Physic) of the Faculty of Education, Khon Kaen University where encourages students to apply constructivist teaching. Bass would be teaching at Demonstration School, a designated laboratory for pre-service teachers under training program on behalf of the university. Second, he volunteered to participate in the study and reflect his teaching practice. Third, the author was a former high school physics teacher at Demonstration School and could draw the understanding on background experiences while collecting and analyzing data. Thus, Bass was an appropriate participant as a case study because he could provide understanding of how constructivist-based physics teaching implementation was developed.

\subsection{Method}

The 16-week research design was conducted to monitor the pre-service teacher's implementation of constructivist physics teaching. The research design was divided into 3 stages. At the first stage, introduction of constructivist theory including applying CLES as a tool was used to reflect how the participant adopted constructivist physics teaching in classroom. At the second stage, the participant's constructivist teaching was measured by using CLES completed by his students. Then, the results reflected participant's constructivist teaching implementation. The reflection was raised for discussion with the author as a teaching coach. At the final stage, the participant was expected to present his development of physics constructivist teaching. The participant was monitored by observing his constructivist learning environment and interviewing. The interview was mainly asked what he had understood the result of the survey and how he would improve constructivist physics teaching in grade 11 more effectively. The insights of understanding how he developed his constructivist physics teaching were to identify factors supporting or hindering the implementation of constructivist physics teaching.

\section{Findings and Discussion}

\subsection{The CLES elements found in the pre-service teacher's implementation of constructivist physics teaching}

\subsubsection{Background}

Bass was a pre-service teaching physics for students in grade 11 at Demonstration School under the Faculty of Education, Khon Kaen University. He was a fourth-year student in Science Education (Physics Teaching). The curriculum was designed for 5 years; 4 years of lecture-based courses and 1 year of training. Bass aimed to be a student-centered teacher. After constructivist teaching theory had been introduced, he decided to participate in the study so as to gain better understanding of the constructivist teaching in practice. Therefore, the author provided research information and conducted an interview with Bass before signing a research consent form to assure that he would follow the research methods by focusing on his teaching attitude and experience. 


\section{[Conversation with Bass, 24-04-2011]}

Author: Why did you decide to participate in the study?

Bass: It seems interesting to me. I have learnt about constructivist only in theory. I would like to apply it into my teaching in practice and understand how a good teacher should be like, and what are the desired qualifications that a teacher should have to urge students to seek for more physics knowledge and make sense of the content by themselves.

Author: Why would you like to adopt constructivist teaching method into your teaching?

Bass: From my personal experience, I think understanding physics can be more exciting rather than just listening and writing what the teacher tells the students to make note. Still, students do not understand how to apply those physics formulas into their real world. I want to change that traditional teaching style to be more creative that leads students to start thinking, questioning and seeking for the answer so that they can realize that physics is important to their life.

Author: What do you understand about CLES?

Bass: It is a survey used to assess the overall constructivist classroom environment. Therefore, it can be employed as a check-list or guideline for planning constructivist-based lessons.

Author: In CLES, there are 5 elements; Personal Relevance (PR), Uncertainty (UN), Critical Voice (CV), Shared Control (SC), Student Negotiation (SN). Which element are you most familiar with?

Bass Um...I think I am most familiar with Personal Relevance (PR) and Student Negotiation (SN). I think SN means that students are allowed to share ideas among classmates and PR refers to the knowledge outside classroom that is used to explain the physics content which can excite students more than typical text. If I could perform all elements of CLES in my teaching, it would be very challenging.

Moreover, the classroom observation, along with interview with Bass's students was used to monitor how his students perceived toward his constructivist learning environment to reflect his implementation of constructivist-based teaching.

[Conversation with Bass's students, 10-05-2011]

Before Bass adopted his constructivist teaching, his students were asked regarding their previous experience in Bass's physics teaching.

Author: How do you feel about studying Physics with Bass?

Student 1: don't like studying physics because it is so difficulty and I cannot understand its formulas. I believe that physics is for whom is good at calculating. Having high score in physics test will be an advantage for admitting into good universities. I always have low score, compared to other friends so that is why I do not like physics.

Student 2: The subject is so difficult. It requires plenty of calculation for the examination.

Student 3: In studying physics, I have to copy notes written on blackboard. However, I sometimes do not understand what teacher tried to explain.

Author: How did you learn in physics classroom, then?

Student 1: I listened to the teacher and conducted laboratory experiment. My teacher sometimes asked us to do the quiz and we had to answer randomly.

Student 2: I did the experiment and paid attention to the teacher's explanation. Anyway, I could not understand all of physics formulas.

Student 3: Um...I think that good calculation skill is basically needed for understanding physics.

Author: How do you normally make sense of physics content?

Student 1: I make sense of science by doing experiment provided by teacher, reading textbooks and listening to teacher.

Student 2: I pay attention to the teacher's lecture.

Student 3: I like science because I can learn it from the surrounding nature.

The findings showed that Bass himself used to have difficulties in understanding physics content when he was in school. He, however, understood how physics was important, so he struggled to link the lessons to the real world. This reflected his effort in raising PR of CLES. He thought that the phenomenon in daily life could be practically adopted to construct learning in classroom. Bass's students, on the other hands, had negative experience in the way that physics teacher guided them to think. They considered physics content very difficult; it required a lot of calculations. They thought that if they could not remember the formulas, they could not understand physics. 


\subsubsection{Students' reflection on the implementation of pre-service constructivist teaching}

In the first semester of academic year 2011, there were 25 students. The classroom observation was used to monitor students' perception toward Bass's abilities in implementing constructivist physics teaching. The questionnaire based on CLES was used to collect statistical data one time per month. The result shows the average of pre and post class scores and standard deviation. (Very often $=5$, Often $=4$, Sometimes $=3$, Seldom $=2$, Never $=1$ )

Table 1. Descriptive statistics of pre and post-test class mean scores of students' perceptions of their classroom learning environment (on the CLES) $(n=25)$

\begin{tabular}{|l|c|c|c|c|c|c|c|c|}
\hline \multirow{2}{*}{ CLES Scales } & \multicolumn{2}{|c|}{ Pre-test } & \multicolumn{2}{c|}{ Post-test 1 } & \multicolumn{2}{c|}{ Post-test 2 } & \multicolumn{2}{c|}{ Post-test 3 } \\
\cline { 2 - 9 } & Mean & S.D & Mean & S.D & Mean & S.D & Mean & S.D \\
\hline Personal Relevance (Learning about the world) & $3.2^{\star}$ & 0.8 & 3.2 & 0.5 & 3.6 & 0.6 & $3.7^{\star}$ & $0.8^{\prime}$ \\
\hline Uncertainty (Learning about science) & 3.0 & 0.7 & 2.9 & 0.6 & 3.1 & 0.4 & 3.2 & 0.5 \\
\hline Critical Voice (Learning to speak out) & $2.7^{\star \star}$ & 0.6 & 3.5 & 0.5 & 3.2 & 0.5 & $3.2^{\star \star}$ & 0.5 \\
\hline Shared Control (Learning to learn) & 2.7 & 0.7 & 2.9 & 0.5 & 2.7 & 0.3 & 2.7 & 0.4 \\
\hline Student Negotiation (Learning to communicate) & $3.3^{\star \star \star}$ & 0.2 & 3.5 & 0.3 & 3.7 & 0.4 & $3.8^{\star \star \star}$ & 0.4 \\
\hline
\end{tabular}

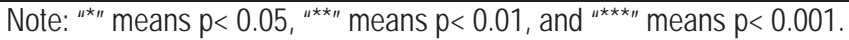

The survey of students' perception toward their constructivist classroom learning environment (see Table 1) indicated that the pre-service teacher implemented 3 out of 5 elements of CLES: PR, CV and SN. Overall, students slightly perceived constructivist classroom learning environment; however, they realized that opportunities to learn about the world, apart from content in textbooks, increased. They were allowed to ask the pre-service teacher, and engage in discussion with other students during their learning activities.

The average of Personal Relevance showed slight improvement, from the pre-test (3.2*) to the post-tests $(3.2,3.6$, $\left.3.7^{*}\right), p<0.05$. It was indicated that Bass had linked physics content to the real world rather than following the teacher's manual.

The average of Student Negotiation showed slight improvement, from the pre-test $\left(3.3^{\star \star}\right)$ to the post-tests $(3.5,3.7$, $\left.3.8^{\star *}\right), p<0.01$. It was indicated that Bass had provided more opportunities for students to participate in discussion with other classmates about their given activities.

The average of Critical Voice showed significant improvement, from the pre-test $\left(2.7^{\star \star *}\right)$ to the post-tests $(3.5,3.2$, $\left.3.2^{\star \star *}\right), p<0.001$. It was indicated that Bass had provided opportunities for students to express their questions and opinions about their learning.

\subsubsection{Pre-service teacher's performance of constructivist physics teaching}

During Bass's teaching performance in classroom, the video was recorded and photos of his given activities were captured randomly by focusing on his reflection of constructivist scheme. In a week, he was responsible for 4 periods; each period lasted 45 minutes. He divided students into 5 - 6 groups for working on activities. From the observation, it was found that he could implement certain constructivist-related perspectives as follows:

Personal Relevance: Bass significantly showed his effort to link students' prior experience to the physics content, using video clips as visual media and other materials to urge them to start questioning and seeking for answer.

In Unit 1 Projectile Motion, the video clips of basketball and football matches were played at the beginning of the lesson. Then, students were asked to find out the possible ways of basketball and football penalty shooting.

In Unit 2 Circular Motion, the video clips of auto racing and satellite motion were used to convey circular motion. The students were asked why motorbike racers mostly bended their bike down, closest to racing track when making a curve around the corner even though this technique caused the high risk of accident to death.

In Unit 3 Rotational Motion, the video clips of cycle wheeling and top rotating were demonstrated to explain why the object can rotate around a pin point.

In Unit 4 Properties of Matters, the video clips of dams, dam forces, and dam construction were presented to illustrate the brief content. The students were asked how the raft floated on the dam and what principles of physics were used.

The video clips and other visual materials were significantly used to challenge students to start thinking, seeking and linking the content with the knowledge outside classroom. However, the students' understanding was considered at 
fundamental level. The pre-service teacher did not fully provide opportunities for students to broaden their knowledge truly. Therefore, students should be inspired to learn through self-discovery, for example, projects.

Uncertainty: Bass prepared experiment for students to prove physics solutions.

In unit 1, the relationship between angles of projectile motion and distance were raised. Bass showed that various angles of projectile motion had an effect on different results in shooting basketball and football.

In unit 2, the experiment of simulated car racing on basin was used to compare with the real car racing on track while making a curve around the corner.

In unit 3, Bass provided an experiment to make students understand the rotational motion of cycle wheeling and gyration, asking students to use their hands to propel the cycle at different positions. The students were also asked to create the experiment by themselves to prove why the different positions, mass and radius affected the rotation motion.

In unit 4, the students were challenged to seek for factors affecting dam construction and floatation. They were also asked to prove the relationship between depth and pressure, pressure and density, and density and volume of liquids.

The objective of the experiments was mainly to explain scientific principles and theories. However, the pre-service teacher took a dominant role, leading students to reach the solution, so-called goal-oriented teaching. Unlike processoriented method, students should have been more promoted to think freely by disregarding the correctness of the final outcome. This would help them understand that there is no absolutely right or wrong process in proving fact under the nature of science.

Critical Voice: The students were offered with more opportunities to solve and answer the physics quiz by themselves from given class activities and materials created by Bass. This resulted in an increase of active participation of students.

In unit 1, the relationship between factors influencing projectile motion and shooting balls was described.

In unit 2, the presentation of making a curve around the corner of motor racers that needed to bend down and accidents that might have caused was illustrated to let students consider the phenomenon.

In unit 3, the presentation of cycle wheeling and top rotating that students were familiar with in daily life was to describe with physics laws why the objects could rotate around a pin point.

In unit 4, engineering dam and floating a raft on the liquid were raised to explain what factors affected massive construction. Also, the relationship between density, volume and force of liquid acting on the structure and design of dam were proved.

Through seeking for answer activities and students' presentation, students reflected both of their understanding and learning concerns. The informal teacher-student relationships enabled students to feel safe and secure to ask questions. It also brought a favorable learning environment to the classroom, raising participation.

Shared Control: The given activities could draw students' attention to search for a solution. Students occasionally designed the experiment based on pre-service teacher's guidance.

In unit 1, students were asked to find out ways leading to answers the quiz. However, students seemed passive and did not have any feedback so that the pre-service teacher had to provoke them.

In unit 2, the pre-service teacher prepared the lesson and activities, providing the students with materials because students were unlikely to participate in controlling the class activities after Bass had assigned them since in unit 1.

In unit 3, the students were more pleased to participate in designing the activities in the topic of pressure of liquid. They presented their ideas of factors affecting the phenomenon. Yet, the pre-service teacher mainly prepared the whole activities.

In unit 4, the pre-service teacher played a key role in designing and controlling the activities in two topics; the speed of bullet and heat and ice movement and its resolution. After experiment, students were likely to be more active in analyzing possible factors influencing the result.

Students partially helped design the overall activities. However, it was obvious that the pre-service teacher prepared most of the lessons and activities. As a result, they did not fully reflect their shared control in determining experiment and activities.

Student Negotiation: The learning environment from physics questions and practical experiment built by Bass led to the cooperation among students, brainstorming and sharing ideas. Students summarized the content as follows:

In unit 1, the vertical and horizontal forces or velocity originated projectile motion.

In unit 2, due to making a curve around the corner with appropriate speed, an accident easily occurred. It meant that force and centripetal acceleration affected speed.

In unit 3, wheeling cycle and rotating top were used to demonstrate rotational motion. The object's mass and radius acted on rotation around a pin point, not a center of mass. 
In unit 4, density, volume and force of liquid affect design and construction of a dam. Because forces acted on object from every direction and that caused the floatation of a raft.

During working on given activities, the pre-service teacher provided more opportunities for students to share ideas through group discussion and experiment in order to prove physics formula. Nevertheless, there was a lack of students' reflection to depict their understanding of nature of science.

After Bass had completed all teaching process, an interview between students and the author was conducted to investigate their perception toward their pre-service teacher's implementation of constructivist teaching.

Author: How do you learn physics in classroom?

Student 1: The teacher simulated a situation and asked us questions. So, we, as in a group, had to utilize physics laws to answer those questions and gave the presentation in front of the class.

Student 2: It was so much fun with experiments that were used to find out the answers.

Student 3: The given experiment led us to construct new knowledge and start questioning. I felt relaxed while sharing ideas to my classmates.

The following interview between Bass and the author was conducted to explore Bass's self-reflection.

\begin{abstract}
Author: How do you feel after finishing teaching?
Bass: I feel better than at the beginning. Form the survey, it shows that students want to learn more actively due to the experiments. They paid attention to watching video clip of motor racing. They shared possible answers of the quiz among friends and tried to explain what they understood. A student said "I just realized that learning physics could be started from the surrounding phenomenon. They participated in the activities and became more confident to express the questions when they did not understand the content.
\end{abstract}

The thing is, I often challenged them to answer the quiz by using activities, experiments and materials such as video clip as a guidance. I always kept in mind to improve my teaching based on constructivist scheme by observing students' behavior in classroom. For example, the students seemed surprised how phenomena were played in video clips. Then, they had some ideas to brainstorm and discuss in group activities by themselves. I motivated them to ask question by disregarding peer pressure. Thus, I feel that it is so important that physics teacher has to truly understand the principles or laws of physics content, along with experience, to challenge students with questions. By linking the content to usual phenomena, students would feel that they got to find out the answer and gain knowledge by themselves.

Overall, at the initial stage of teaching practice, the pre-service teacher significantly reflected 3 of 5 elements based on CLES including PR, CV and SN. These 3 elements contributed to constructing knowledge of students by linking knowledge outside classroom and actual experience to make them understand physics formulas. Nonetheless, the preservice teacher did not challenge students at the advanced level that could broaden their understanding of nature of science thoroughly. As a consequence, students were unlikely to explain or utilize the knowledge effectively.

\title{
4.2 Barriers found in the pre-service teacher's implementation of constructivist physics teaching
}

There were barriers found in the constructivist learning environment that caused the unexpected result in certain elements of CLES as follows:

1) Prior experience of students

Students were familiar with the way that teacher asked them to make note what he/she said without depicted explanation. They were not used to constructing knowledge by conducting experiments and surrounding phenomena. They found it difficult to initiate ideas to work in group. Therefore, passive learning style affected constructivist learning environment.

2) Attitude of pre-service teacher

From observation, Bass had a belief that students should have realized how physics was important to their daily life and how physics principles derived from before they became aware of seeking for more knowledge. Thus, Bass prepared materials, video clips, and applied equipment to inspire students to learn.

\section{Conclusion}

CLES is used to reflect elements required for improving the level of student-centered scheme. Through the observation and interview, it is found that the pre-service teacher could significantly perform 3 elements: personal relevance (PR), 
student negotiation (SN), and critical voice (CV). There were 2 elements that Bass could not completely implement: uncertainty (UN) and shared control (SC). However, his prior experience was beneficial to his physics teaching so that he prepared practical materials to portray and linked the content to the easy-to-understand nature. Due to his limited experience in actual teaching, he could not successfully in implementing constructivist teaching.

Even though students were able to design the experiments, set the objectives and solve the question in challenging activities by themselves, Bass's constructivist elements in terms of uncertainty (UN) and shared control (SC) was rated low. Because of his well-prepared activities, students did not have an opportunity to fully initiate and construct their knowledge. According to Good, Wandersee \& Julien (1993) the nature of science is an essential instrument in constructivist view to eliminate the need to support what appear to be statement that are achieving higher levels of science literacy. Hence, Bass was suggested to develop his teaching to be more challenging in his future teaching which should raise the level of understanding nature of science and promote students' self-discovery based on student-centered teaching method.

Furthermore, the nature of science is used to explain physics concept learning management. Consequently, the prospect teacher should practice his skills in creating activities and sustain his self-development that support constructivist teaching and learning. When the teacher can reflect himself, for example, the reflection of constructivist teaching, as well as students reflect their role in learning, for example, the reflection of their perception through the survey, the more favorable learning environment can be improved along with the more experience of teacher gained from students' comments over time.

For the future study, the modified framework will be used to promote constructivist learning environment for the prospect physics teachers. The study phase 2 will start from the development of personal relevance, critical voice and student negotiation because these three elements are more understandable and accessible in the perspective of nonexperience teachers. As a result, they should be able to initiate challenging activities for student more effectively and prompt for further development of all five elements in the later phase.

\section{References}

Aldridge, J.M., Fraser, B.J., Taylor, P.C., \& Chen, C.C. (2000). Constructivist learning environments in a cross-national study in Taiwan and Australia. International Journal of Science Education 22: 37-55.

Creswell, J. W., \& Plano Clark, V. L. (2011). Designing and conducting mixed methods research. (2nd ed.). Thousand Oaks, CA: Sage. Education Sector:UNESCO. (2003). Project INSITE, 2000, from http://www.utexas.edu/education/LTC/zOLDfiles/research/index.html

Fraser, B. J. (1986). Classroom environment. London: Croom Helm.

Fraser, B. J. (1994). Research on classroom and school climate. In D. Gabel (Ed.), Handbook of research on science teaching and learning (pp. 493-451). New York:

Fraser, B. J. (2002). Learning environments research: Yesterday, today and tomorrow. In S. C. Goh \& M. S.

Good, R.G., Wandersee, J.H., \& St. Julien, J. (1993). Cautionary notes on the appeal of the new "ism" (constructivism) in science education. In K. Tobin (Ed.), The practice of constructivism in science education. Hillsdale, NJ: Lawrence Erlbaum.

Office of the National Education Commission: Office of Prime Minister Kingdom of Thailand. (1999). Thai national education act of B.E. 2542. Bangkok: Kuruspa Press.

Steffe, L. P., \& Gale, J. (1995). Constructivism in education. Mahwah, New Jersey: Lawrence Erlbaum Associates.

Taylor, P. C., Fraser, B. J., \& Fisher, D. L. (1997). Monitoring constructivist classroom learning environments. International Journal of Educational Research, 27, 293-302.

Tobin, K. E. (1993). The practice of constructivism in science education. Hillsdale, NJ: Lawrence Erlbaum. 